\title{
Congreso PANLAR 2018
}

\section{Estimados Miembros de la Sociedad Argentina de Reumatología,} Lectores de la Revista Argentina de Reumatología, amigos:

Con gran placer y alegría, escribo esta última invitación al ya inminente $20^{\circ}$ Congreso PANLAR 2018, en Buenos Aires.

Con la participación de todos ustedes, este Congreso PANLAR será un gran evento científico y social. Por el momento, este Congreso PANLAR parece que se constituirá en el Congreso record PANLAR en numerosos rubros: números de inscriptos, números de trabajos científicos recibidos, número de ponentes, número de compañías que apoyan el congreso, entre otros. Estamos seguros, además, que será un gran evento en cuanto a lo científico, lo académico, y la innovación. Desde la Sociedad Argentina de Reumatología, la comisión directiva, y muchos de sus miembros no pertenecientes a la misma, han trabajado en forma muy intensa, constante y desinteresada, para que este evento sea inolvidable. Deseamos dejar en nuestros amigos Reumatólogos Latino Americanos y Pan Americanos, un recuerdo imborrable.

También hablamos de lo Social, porque el juntarnos, conversar, y crear lazos es uno de los factores más importantes por lo que los Congresos presenciales, creo, no podrán ser reemplazados por eventos virtuales. Es intención de PANLAR facilitar esos momentos de encuentro.

La Sociedad Argentina de Reumatología (SAR) se enorgullece y alegra profundamente de ser el anfitrión de este importantísimo evento. Agradecemos especialmente el apoyo de todas las filiales de la SAR, y especialmente el de la filial Tucumán, que resignó el Simposio de Otoño que le había sido otorgado para apoyar este Congreso PANLAR.

Bajo el lema: "Por un PANLAR que, afirmado en el presente, salta al futuro", el $20^{\circ}$ Congreso PANLAR coloca la innovación, participación y pertenencia como sus pilares fundamentales.

Queremos, y estamos seguros de lograr con tu ayuda, que cada uno encuentre en PANLAR y en su Congreso, un lugar, su lugar, de crecimiento científico y humano.

¡Los esperamos!, para entre todos seguir construyendo este renovado PANLAR.

\section{Enrique Soriano}

Presidente de la SAR

Presidente de PANLAR 